\title{
Development of a low-cost autonomous oceanographic observation vehicle
}

\author{
S. Gomáriz, J.Prat, A.G. Ruiz, J. Sole, P.Gayá and J. Del Rio. \\ Department of Electronic Engineering. Universitat Politècnica de Catalunya. \\ Av. Victor Balaguer s/n. 08800. Vilanova i la Geltrú. Spain. \\ Phone: +34 938967781, Fax: +34 938967700, E-mail: spartacus.gomariz@upc.edu
}

\begin{abstract}
This work proposes the development of a low-cost ocean observation vehicle. This vehicle, a hybrid between Autonomous Underwater Vehicles (AUV) and Autonomous Surface Vehicles (ASV) moves on the surface of the sea and makes vertical immersions to obtain profiles of a water column according to a pre-established plan. Its design means production costs are low and efficiency is increased. Also, the vehicle is able to make high resolution space and time measurements simultaneously. GPS navigation allows the platform to move along the surface of the water while a radio-modem provides direct communication links and telemetry. The vehicle measures $1885 \mathrm{~mm}$ by $320 \mathrm{~mm}$ wide. It weighs $76 \mathrm{~kg}$. It navigates at a speed of $1.5 \mathrm{~m} / \mathrm{s}$ at $80 \%$ at full propulsion power and reaches a maximum depth of $20 \mathrm{~m}$. It is a vehicle of electrical propulsion with an autonomy of 3-5 hours. This work outlines the mechanical and electronic design of the vehicle, as well as considerations for navigational and immersion experiments.
\end{abstract}

\section{INTRODUCTION}

Despite major advances in ocean research by oceanographic ships and anchorages, tests on the marine environment are still insufficient. The limitations of conventional oceanic observation platforms cannot carry out tests in the sea and provide the required space and time measurements. For this reason and with the aid of recent technological advances, the development of new oceanographic observation platforms which are able to carry out high-resolution space and time interdisciplinary measurements simultaneously, have been tested. Observation platforms referred to as Gliders, Autonomous Underwater Vehicles (AUVs) and Autonomous Surface Vehicles (ASVs) have already been designed [1] [2]. This project proposes the development of a low-cost oceanic observation vehicle which is a hybrid between the AUVs and ASVs. The vehicle moves along the surface of the sea and makes vertical immersions to obtain vertical profiles of a water column in agreement with a pre-established plan [3] [4]. These two characteristics of the observation platform lower the production costs and increase its efficiency. GPS navigation will allow the platform to move along the surface of the water while a radio-modem will provide direct communication links and telemetry.

This work is organized as follows: In section II a prototype vehicle is mechanical designed. After regard an autonomous navigation control system is designed in section III. Section IV deals with the communication with shore through a graphical user interface. Section V presents the experimental results of navigation. Finally, section VI presents the conclusion.

\section{MECHANICAL DESIGN OF THE VEHICLE}

The design proposed here is a prototype which will have to be modified. The platform design is made up of a support structure on which the steering and propulsion mechanisms are attached. This structure is not watertight, thus allowing us to drill holes wherever required.

A watertight cylindrical module is located inside the support structure. It houses the immersion actuator and the electronics control, as well as the power supply provided by the batteries [5].

\section{A. Support Structure}

As figure 1 shows, the support structure is made up of a PVC cylinder, $1.2 \mathrm{~m}$ in length by $32 \mathrm{~cm}$ in outer diameter. The simple construction means it is easy to make modifications. The final result is a platform which can house the bulky elements of the vehicle such as the batteries and the immersion actuator in the minimum space possible. The main Seaeye $\mathrm{e}^{(\mathrm{TM})}$ propulsion engine is located at one the end of the support structure [6]. This engine, without brushes, runs on a supply voltage of $24 \mathrm{~V} \mathrm{DC}$ and nominal current of $5 \mathrm{~A}$, which provides a maximum thrusting of $110 \mathrm{~N}$ to $950 \mathrm{rpm}$ [7].

Individual Seabotix ${ }^{(\mathbf{T M})}$ engines are located on the sides of the cylinder. These engines have a maximum thrust of $25 \mathrm{~N}$ at a maximum power of $80 \mathrm{~W}$ and are powered with $24 \mathrm{~V}$ DC [8]. When these engines are used, the course of the vehicle can be altered. This solution was favoured instead of a rudder system with a hydraulic cylinder because its construction is simple [9].

The engines, located on the sides of the device are attached to the support structure by means of a stainless steel telescope tube that allows the spindle, located on both of the vehicle's engines, to be altered during testing.

The main engine is attached to the support structure by means of a stainless steel tube and mechanized nylon blocks provide adequate rigidity.

Finally, depth and direction auto-stabilizers are located on the stern once again to ensure stability. The bow is finished with a carbon fibre hemisphere.

\section{B. Watertight Module.}

As figure 1 shows, the watertight module contains the set of immersion equipment, the electronic signal reception modules and engine control, and the power supply batteries. 


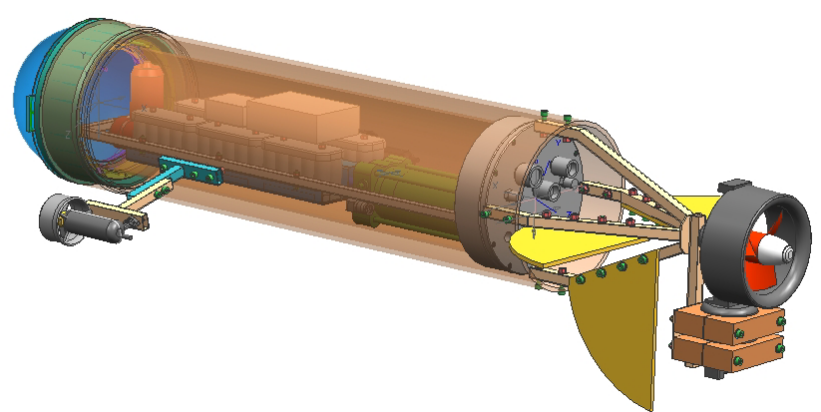

Figure 1. Frame

All these parts are joined to the watertight PVC cylinder by means of a metallic structure. See below.

The watertight module is covered in black nylon. An o-ring and 12 M6 screws guarantee watertightness.

The design of the emersion and immersion equipment is composed of a commercial pneumatic stainless steel cylinder with a displacement of $1500 \mathrm{~cm} 3$ and a linear electrical actuator which can cover a maximum distance of $200 \mathrm{~mm}$ and a thrust force of $3 \mathrm{KN}$. See figure 2.

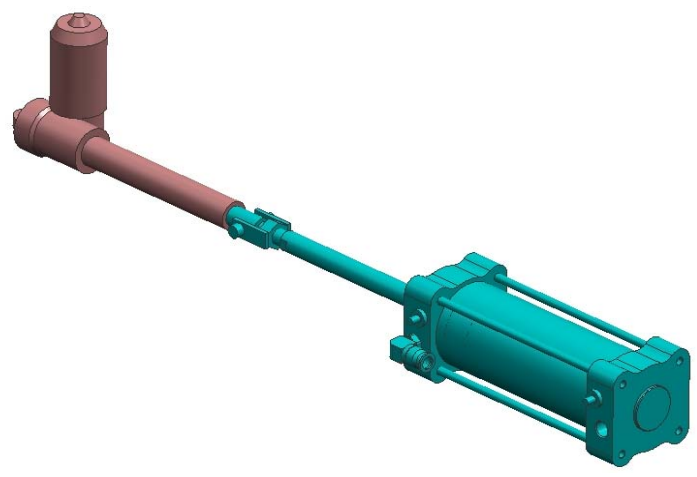

Figure 2. Emersion and immersion actuator

\section{Complete structure of the vehicle.}

Figure 3 and figure 4 show the external structure and watertight module of the constructed vehicle, respectively.

It is worth highlighting, that the position of the center of gravity ensures stability in immersion/emersion operations.

The payload works out at $5 \mathrm{~kg}$, approximately, on a gross weight of the $76 \mathrm{~kg}$ platform.

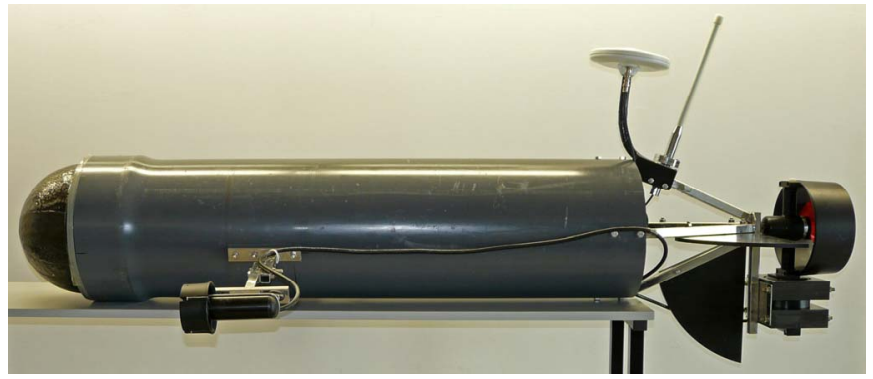

Figure 3. Constructed vehicle.

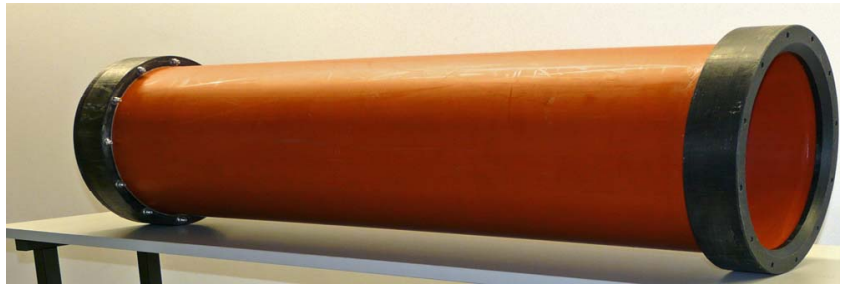

Figure 4. Constructed watertight module

\section{ELECTRONIC DESIGN. CONTROL PHASE}

The autonomous navigation control system is made up of an embedded computer and the elements necessary for communication, navigation and propulsion and data acquisition. Safety elements are also included [10]. In figure 5 the diagram for the autonomous control of the vehicle is described.

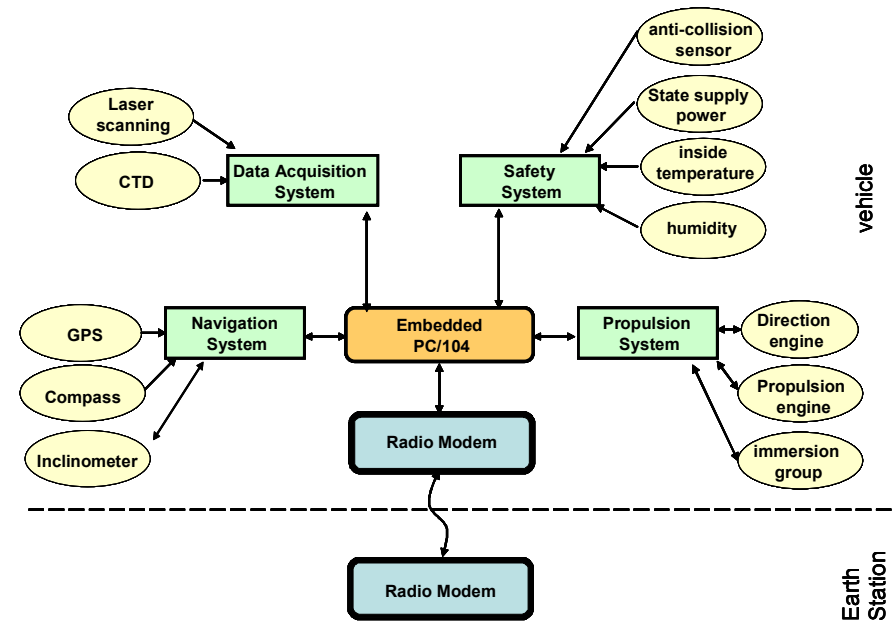

Figure 5. Diagram of the autonomous control system

Communication between the vehicle and the station located on shore is bidirectional and a Farell Instruments ${ }^{(\mathrm{TM})}$ industrial modem T-MODC48 has been used. Its features include a data rate of $4800 \mathrm{bps}$, protocol-transparent and a configurable carrier power of $100 \mathrm{~mW} / 5 \mathrm{~W}$ that allows a maximum range of $10 \mathrm{~km}$ and $+/-1 \mathrm{ppm}$ stability level from $-30^{\circ} \mathrm{C}$ to $60^{\circ} \mathrm{C}$ [11].

A PC/104 embedded computer (PM-6100 AEWIN) makes up the central control of the vehicle, see figure 6 . It has an embedded AMD ${ }^{\circledR}$ Geode ${ }^{\mathrm{TM}}$ LX800 CPU up to $500 \mathrm{MHz}$. This is of limited size, weight and power consumption ( $\max 12 \mathrm{~W})$. It also has a low heat loss [12]. It is managed by a Windows XP operating system stored in a compact flash memory which provides good protection from vibration.

The propulsion control system is a SSC32 Lynxmotion driver. See figure 7. This transforms the RS232 signal from the $\mathrm{PC} / 104$ in a modulated PWM signal that acts on the engine power drivers. This servo-controller has 32 channels with 1uS$0.09^{\circ}$ resolution and $1 \mathrm{uS} / \mathrm{Second}$ speed. This can work at a velocity of $2400,9600,38.4 \mathrm{k}, 115.2 \mathrm{k}$ bauds [13] 


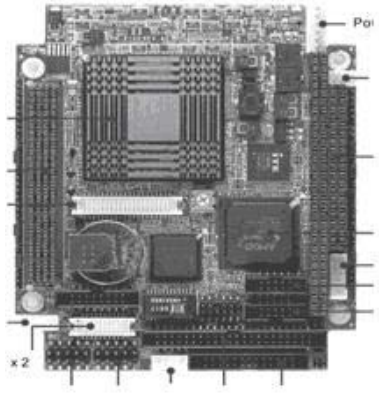

Figure 6. PC/104+ PM-6100

Several power drivers have been developed to adapt the modulated PWM signal received from the SSC32 so that the vehicle's engines can execute the control orders.

A. Power steering driver. The steering orders received are transferred to individual adjustable-speed drives that control the engines responsible for moving to the left and right. These adjustable-speed drives incorporate the power electronics necessary to adapt to the engines changing requirements.

B. Power driver of immersion/emersion. The immersionemersion orders are applied to a control circuit that acts on the engine-cylinder equipment.

This control circuit incorporates a microcontroller PIC $16 \mathrm{~F} 88$ that interprets the signal received and consequently executes the stop/immersion/emersion orders on the electrical engine of the immersion/emersion equipment.

The pneumatic cylinder incorporates individual magnetic limit switches which can block the electric engine's actuators and also act as a security system limiting the total displacement of the cylinder.

C. Power driver for propulsion. The propulsion orders are processed on a microcontroller PIC16F873, which provides the control signal via RS485 to the propulsion engine. This engine includes the control and power electronics necessary to decode the orders received via RS485.

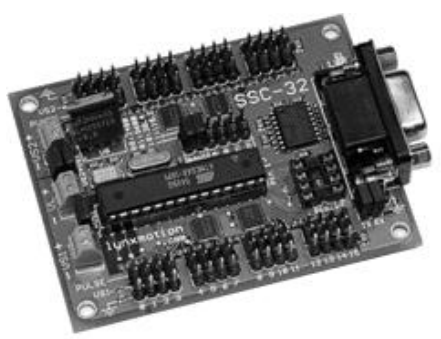

Figure 7. Controlled SSC32

The navigation system is a digital compass and a three-axis inclinometer, PNI TCM-2.6, see figure 8a. The TCM 2.6 is a 3axis tilt-compensated compass-heading (also known as azimuth, yaw, or bearing angle) module with electronic gimballing to provide accurate heading, pitch, and roll measurements over a $\pm 50^{\circ}$ tilt range. This high-precision (heading accuracy $0.8^{\circ}$ ), high-resolution (Compass heading $\left.0.1^{\circ}\right)$ navigation system runs on low power ( $<20 \mathrm{~mA}$ typical draw) [14].

The navigation system also has a global positioning system GPS, Magellan DG14 ${ }^{\mathrm{TM}}$, which provides the precise location of the vehicle during a mission, see figure $8 b$.

The DG14 ${ }^{\mathrm{TM}}$ is a sub-meter GPS+Beacon+SBAS receiver. It incorporates signals from Satellite Based Augmentation Systems (SBAS), such as WAAS, EGNOS \& MSAS, or an embedded beacon receiver, to provide sub-meters differential positioning. DG14 can emit SBAS ranging, ephemeris and differential corrections through the serial port. Although DG14 offers three standard RS232 ports, it is also capable of single port operation.

It can provide up to $20-\mathrm{Hz}$ precise three-dimensional positions and raw data for real-time guidance and navigation [15].

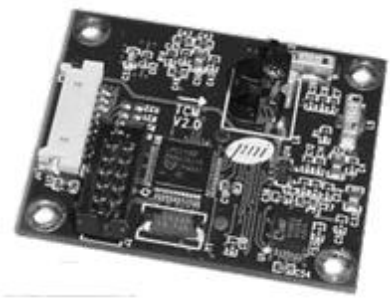

(a)

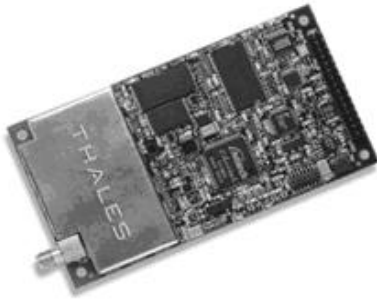

(b)
Figure 8. Navigation System. (a) PNI TCM-2.6 (b) DGPS, DG14

All this equipment is assembled inside two PVC boxes, as seen in figure 9. One box houses the $\mathrm{PC} / 104$ with the navigation system and the other is equipped with the propulsion system. For both boxes a power bus which uses $24 \mathrm{~V}, 12 \mathrm{~V}$ and $5 \mathrm{~V}$ has been installed. These voltages are generated from $6 \mathrm{Ni}-\mathrm{Cd}$ batteries, $24 \mathrm{~V}$ nominal voltage and $21 \mathrm{AH}$ capacity, through a power stage implemented using switched dc-dc converters, located in a separate box.

Safety elements for the vehicle and a data acquisition system will be developed in the second stage of the project. Figure 9 shows the layout of all the elements in the watertight module.



Figure 9. Inside layout of the watertight module 


\section{SOFTWARE DESIGN. TRACKING STATION}

The vehicle needs user interaction in terms of control parameters, operational verification and data acquisition and downloading. A program has been designed which reads/writes the data received/sent by radio-modem, checks for transmission errors and represents the information graphically. Figure 11 shows the graphical user interface (GUI). The GUI has a two-page front-end. The main page incorporates direction, roll and pitch angles indicators and also an artificial horizon to view the data transmitted by the compass / inclinometer. This page also includes a series of Scrollbars and buttons to control the vehicle's engine. The second page presents the user with each of the parameters that the GPS receiver provides using TextBox and a variety of geo-maps to locate the position of the vehicle.

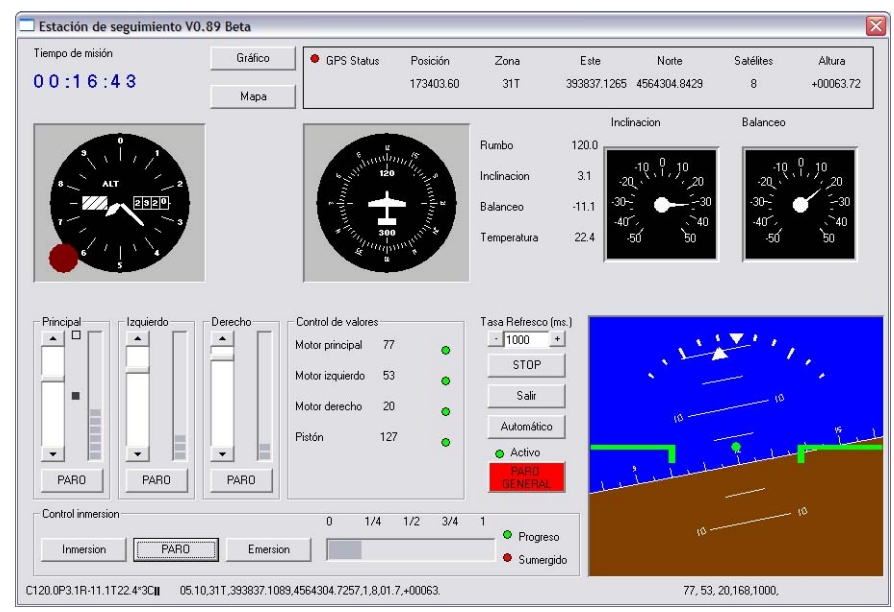

(a)

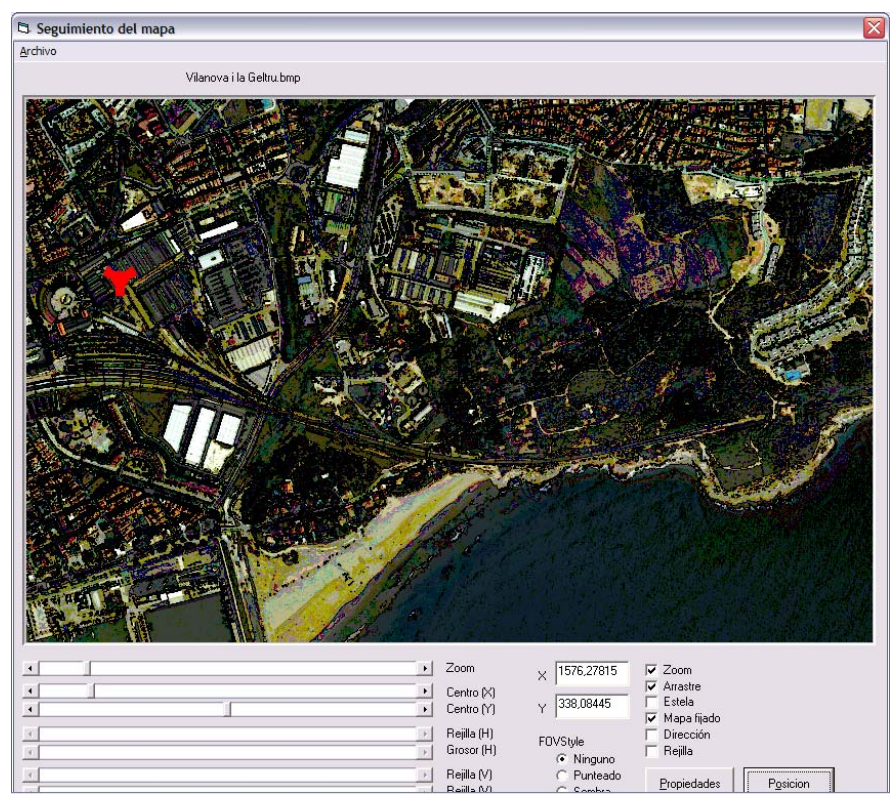

(b)

\section{EXPERIMENTAL TESTS}

When the vehicle was initially placed in the water, balance had to be adjusted. It was obtained by incorporating a $3.6 \mathrm{~kg}$ ballast in the prow and a $1.5 \mathrm{~kg}$ push in the stern. This was sufficient to allow the navigation and immersion tests to begin. In the navigation test the speed was approximately $1,5 \mathrm{~m} / \mathrm{s}$ with the control of the propulsion engine at $80 \%$ at full power. By using the lateral engines at full power and decreasing the propulsion of the first engine the trajectory, variation is obtained very easily. The immersion tests were carried out with complete normality acting on the engine-cylinder equipment.

The proper operation of the autonomous control system has also been validated experimentally. We could successfully operate in manual mode on the vehicle's engine from the ground station and a second phase, a steering control algorithm will be implemented in the embedded PC module. With regard to position and attitude of the vehicle, after a calibration process, were obtained and sent to the earth station. See figure 11.

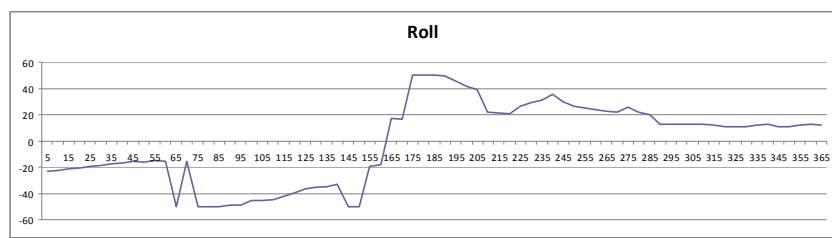

(a)

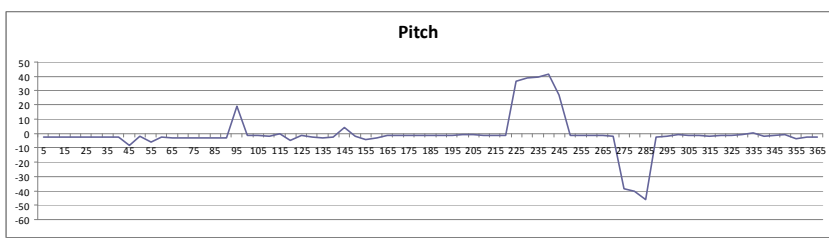

(b)



(c)

Figure 11. Attitude vehicle (a) Roll $\quad$ (b) Pitch $\quad$ (c) Heading

\section{CONCLUSIONS}

The result so far is a robust platform which is relatively small and light, factors which facilitate its manageability and operability. To sum up we can say that a low-cost oceanic observation platform has been developed which is able to navigate on the surface of the sea and make vertical immersions to obtain water column profiles. 


\section{ACKNOWLEDGMENT}

This work has been funded by the Spanish Ministry of Education and Science and the European Union (FEDER), project $n^{\circ}$ : CTM2006-12072/MAR.

\section{REFERENCES}

[1] Meyrowitz, A.L.; Blidberg, D.R. and Michelson, R.C. "Autonomous vehicles" Proceedings of the IEEE. Volume 84, Issue 8, pp 1147 - 1164. 1996.

[2] Blidberg, D. R. "The development of Autonomous Underwater Vehicles (AUV); A brief summary" Autonomous Undersea Systems Institute publications (AUSI), ICRA, Seoul, Korea, May 2001.

[3] Dabholkar, N., Desa, E., Afzulpurkar, S., Madhan, R., Mascarenhas, A.A.M.Q., Navelkar, G., Maurya, P.K., Prabhudesai, S., Nagvekar, S., Martins, H., Sawkar, G., Fernandes, P. and Manoj, K.K. " Development of an autonomous vertical profiler for oceanographic studies," Proceedings of the International Symposium on Ocean Electronics (SYMPOL-2007), 11-14 December, Cochin, India, pp. 250-256. 2007.

[4] Byron, J. and Tyce, R. "Designing a Vertical / Horizontal AUV for Deep Ocean Sampling" Proceedings of MTS/IEEE Conference and Exhibition Oceans 2007. Sept. 29 2007-Oct. 4. Vancouver, Canada pp. 1-10. 2007

[5] Egeskov, P., Bjerrum, A., Pascoal, A. Silvestre, C., Aage, C. and Wagner Smith, L. (1994) Design, construction and hidrodinamic testing of the AUV MARIUS. Proceedings of the AUV 94, Cambridge, Massachusetts, USA.

[6] Seaeye, http://seaeye.com/thrusters.html

[7] DeWijs, B. "AUV/ROV propulsion thrusters". Proceedings of MTS/IEEE Conference and Exhibition OCEANS 2000. 11-14 September, Providence, Rhode Island, U.S.A, pp 173 - 176 vol.1. 2000.

[8] Seabotix, http://seabotix.com

[9] Desset, S., Damus, R., Hover, F., Morash, J. and Polidoro, V. "Closer to deep underwater science with ODYSSEY IV class hovering autonomous underwater vehicle (HAUV)". Proceedings of MTS/IEEE Conference and Exhibition Oceans 2005 - Europe, 20-23 June, Brest, France, pp. 758-762 Vol.2. 2005.

[10] Desa, E., Maurya, P.K.,Pereira, A., Pascoal, A.M., Prabhudesai, R.G., Mascarenhas, A., Madhan, R., Matondkar, S.G.P., Navelkar, G., Prabhudesai, S. and Afzulpurkar, S. (2007) Small Autonomous Surface Vehicle for Ocean Color Remote Sensing. IEEE Journal of Oceanic Engineering, April, pp. $353-364$ Vol. 32, Issue 2.

[11] Farell, http://www.farell-i.com/farell/eng/productos.php

[12] Aewin

http://www.aewin.com.tw/main/product_info.aspx?fid=2\&sid=3\&sname $=$ Embedded+Board \&pname $=$ PM$6100 \&$ tname $=\mathrm{PC} \% 2 \mathrm{~F} 104+\mathrm{CPU}+$ Module $\&$ fname $=\& \mathrm{pid}=27$

[13] Lynxmotion, http://www.lynxmotion.com/Product.aspx?productID=395\&CategoryID= 52

[14] PNI, http://www.pnicorp.com/products/all/tcm-2-6

[15] Magellan, http://pro.magellangps.com/en/products/product.asp?PRODID=174 